\title{
La reciprocidad de la religión y la bioética en la medicina y la investigación médica
}

\author{
Raymond Barfield, Paige Martin y Juan de Dios Peña \\ Traducción: Luis Alvarenga \\ Departamento de Filosofía \\ UCA, San Salvador
}

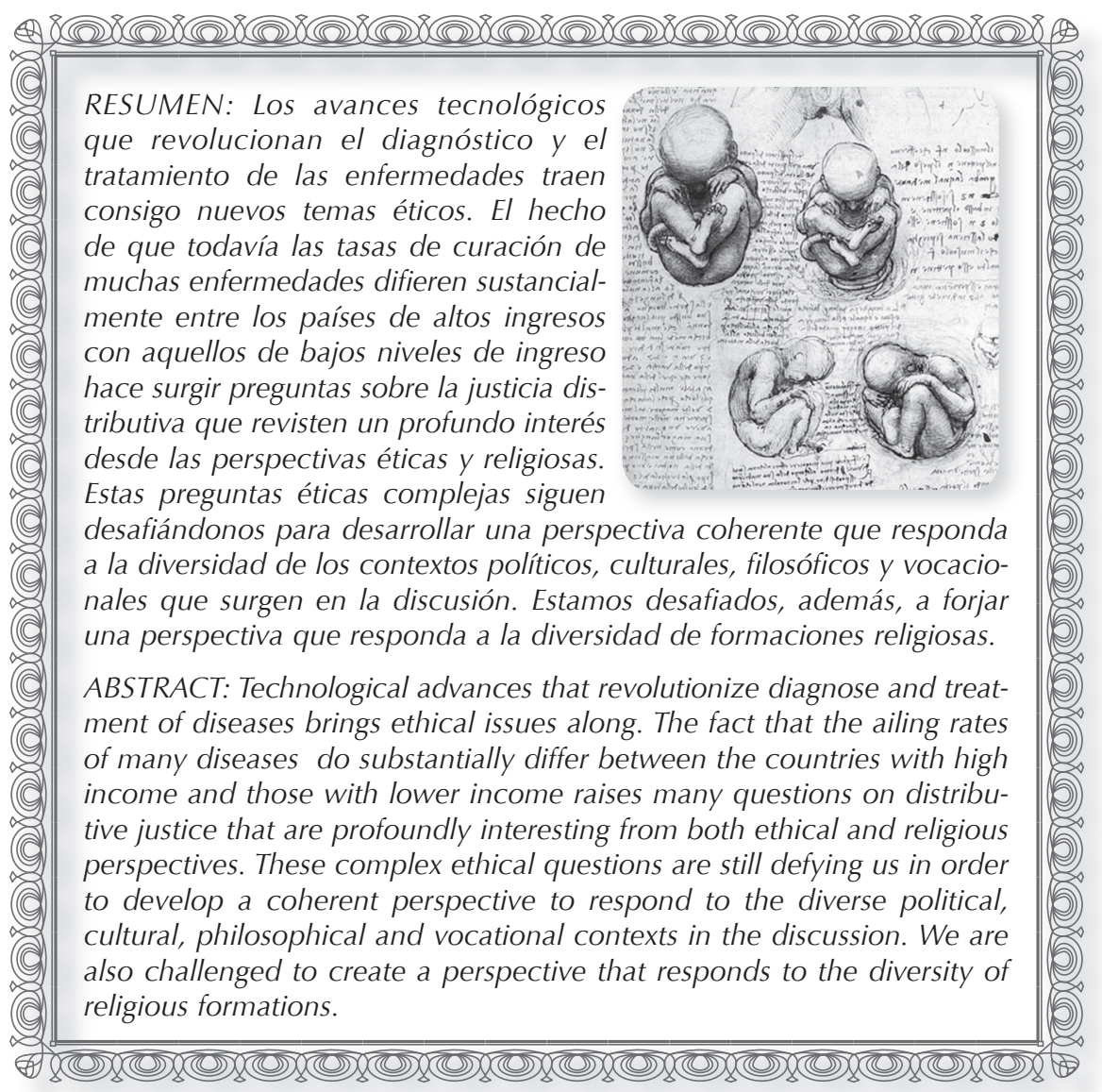




\section{Introducción}

os fines de la medicina y los fines de la investigación médica se traslapan entre sí, dado que ambas están enfocadas, en última instancia, en mejorar la salud, la calidad de vida, la duración de la vida y el florecimiento humano. $Y$, a veces, estas disciplinas pueden diferir de forma importante, puesto que la primera se interroga por cuál puede ser el mejor interés de un paciente concreto, y la segunda siempre implica una prueba en la cual el problema de "lo que es mejor para un paciente en específico" no puede saberse hasta que la prueba de la investigación esté concluida. Pero es cierto también que la toma de decisiones éticas es una meta fundamental común a la medicina clínica y a las investigaciones clínicas de todo tipo. Se han hecho grandes esfuerzos para explicar ampliamente los elementos de la toma de decisiones comunes a ambas disciplinas, tomando en cuenta el hecho de que semejante deliberación debe ocurrir necesariamente en ámbitos pluralistas. Esta meta se ha perseguido vigorosamente a partir de la exposición de abusos humanos de tipo moral, tales como los que se pusieron en evidencia en los procesos de Nuremberg, en la investigación de Tuskegee sobre la sífilis patrocinada por el Servicio de Salud Pública de Estados Unidos y por el comité asesor del presidente Clinton sobre los experimentos de radiación en humanos. El fruto práctico de estos esfuerzos ha sido

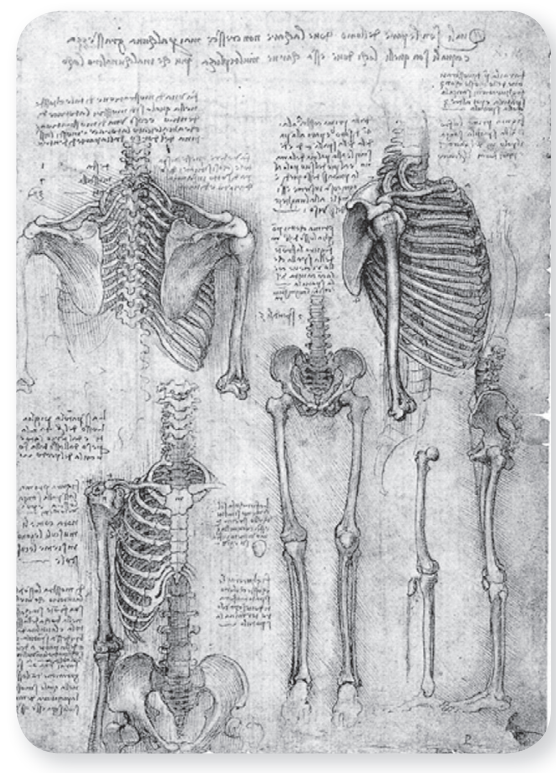

la producción de documentos altamente influyentes, como el Informe Belmont, la Declaración de Helsinki y sus diferentes versiones, las líneas de trabajo producidas para la discusión internacional por el Consejo de Organizaciones Internacionales de las Ciencias Médicas (CIOMS, por sus siglas en inglés) y, más recientemente, la adopción de la Declaración Universal de la Bioética y los Derechos Humanos de 2005, por parte de la Organización de Naciones Unidas para la Educación, la Ciencia y la Cultura (UNESCO). El común denominador de estos esfuerzos son los principios como el respeto a las personas, la beneficencia y la justicia.

Estos conceptos comunes de moralidad son, ciertamente, importantes en el compromiso moral de la mayoría de las tradiciones 
religiosas, dentro de las cuales hay una riqueza de historias sobre la lucha con el significado de la enfermedad, el sufrimiento, la muerte y la pregunta sobre la naturaleza del mundo en que vivimos. Dicho esto, los documentos que son las referencias más comunes cuando surgen cuestiones éticas en ambientes médicos o investigativos no son específicamente documentos religiosos, y además no reivindican el hecho de depender o de referirse a alguna tradición religiosa en específico. Representan un esfuerzo importante para encontrar un lenguaje y un mecanismo para referirse a problemas éticos complejos en un mundo cuya historia, política, economía y fe son heterogéneas. ¿Cómo puede un esfuerzo tan loable comprometerse con las tradiciones religiosas?

Hacerse esa pregunta es, en muchas formas, formularse una pregunta que está respondida en la práctica diaria, por cuanto muchas personas de diferentes formaciones se reúnen en formas muy prácticas para llevar a cabo actividades concretas, las cuales son éticamente ricas y que suelen ser éticamente complejas. De muchas maneras, las preguntas éticas que rodean a la atención e investigación médica se han vuelto más urgentes que nunca, tanto para las instituciones médicas y religiosas que traen a cuenta la historia de sus propias deliberaciones. $Y$, debido en parte a que muchas de las personas que participan en la atención e investigación médica están comprometidas de forma significativa en una tradición médica, el sentido de urgencia se extiende a la pregunta sobre cómo las comunidades religiosas se comprometen con la comunidad médica e investigativa y cómo los esfuerzos de un grupo afectan el rumbo y los esfuerzos del otro. Las dos últimas décadas han visto un aumento sin precedentes en el intercambio internacional de información e ideas. Este hecho ha posibilitado una propagación más rápida de información útil, y, además, ha descubierto cada vez más disparidades en el acceso a la tecnología, la disponibilidad de recursos y valores éticos, todos los cuales conllevan la ética de la medicina y de la investigación médica cuando se consideran desde una perspectiva global.

Los avances tecnológicos que revolucionan el diagnóstico y el tratamiento de las enfermedades tales como el cáncer traen consigo nuevos temas éticos. Y el hecho de que todavía las tasas de curación de muchas enfermedades difieren sustancialmente entre los países de altos ingresos con aquellos de bajos niveles de ingreso hace surgir preguntas sobre la justicia distributiva que revisten un profundo interés desde las perspectivas éticas y religiosas. Estas preguntas éticas complejas siguen desafiándonos para desarrollar una perspectiva coherente que responda a la diversidad de los contextos políticos, culturales, filosóficos y vocacionales que surgen en la discusión. Estamos desafiados, además, a forjar una 
perspectiva que responda a la diversidad de formaciones religiosas.

Cuando se discuten estas cuestiones una consideración importante es aquella de la supervisión ética de la investigación médica internacional. Las líneas del Consejo de Organizaciones Internacionales de Ciencias Médicas afirman que los investigadores y las instituciones de los países con altos niveles de ingresos que patrocinan investigaciones en las naciones con bajos ingresos tienen una obligación ética para mejorar la capacidad de proteger a los participantes humanos en esos países. Sin embargo, en una investigación en la que participaron 203 investigadores clínicos en países de bajos ingresos, el 44\% informó que sus estudios no fueron supervisados por el ministerio o el departamento de salud del país en que se encontraban trabajando; mientras que el $25 \%$ informó que sus estudios no pasaron ningún tipo de inspección de parte de un comité ético de investigaciones, de una junta institucional de inspección o del ministerio o departamento de salud. Los investigadores tampoco reportaron un trabajo de supervisión en publicaciones de alto nivel, mientras que el Comité Internacional de Editores de Publicaciones Médicas establece que los informes de investigaciones que involucran a sujetos humanos documenten que se hayan establecido mecanismos para proteger a estos sujetos. En la medida en que los países en desarrollo establecen estos comités éticos de investigación, ¿qué papel, si es que lo tiene, deben jugar las instituciones religiosas de estos países?

\section{Conceptos bioéticos y conceptos religiosos}

L os conceptos éticos más comunes que se usan en la discusión de desafíos éticos particulares son el respeto a las personas, la justicia y la beneficencia. Una forma en la que la relación de bioética y religión se suelen considerar es preguntar por el origen de estos conceptos centrales. En función de que la idea del "respeto a las personas" tenga un significado sustancial, uno debe poder decir qué es una persona, qué significa respetar a una persona y por qué ese respeto es una obligación moral. Asimismo, es importante definir qué significa la justicia en la bioética, también es importante poder decir porqué la justicia concebida de esta forma le da obligaciones a cualquier persona. Finalmente, en el caso de la beneficencia no es sólo importante decir qué es lo que constituye los bienes de la persona, pero también por qué yo o alguien más debe preocuparse por dichos bienes.

Los orígenes históricos de la bioética contemporánea aclaran que en la bioética no estamos simplemente dilucidando entre varias opciones que alguien debería elegir. Con frecuencia decimos que 
hay caminos que son moralmente mejores que otros. Tratamos de hacer lo correcto. Incluso cuando lo correcto no está claro y ello genera desacuerdos entre la gente con preocupaciones morales. Aún así, el objetivo es siempre hacer lo correcto, en la medida en que podamos discernirlo. Cuando la bioética contemporánea nació, en los procesos de Nuremberg, nació no sólo porque a alguna gente le pareció que los experimentos nazis eran disgustantes. No fue porque los investigadores objetivos estuvieran preocupados porque la elección de métodos para descubrir la capacidad del cuerpo humano para resistir el frío y el calor extremos era científicamente insana, fue, más bien, debido a que las acciones de los médicos nazis que condujeron los experimentos estaban equivocadas y no meramente equivocadas, sino profunda, horripilante y absolutamente equivocadas.

La bioética no surgió con principios que luego se aplicarían para descubrir qué tipo de investigación es moralmente óptima y cuál es moralmente sospechosa. Antes bien, la ética surgió con la claridad de que una serie de acciones era con mucha certeza equivocada y solamente entonces, a partir de este conocimiento (tan cierto como cualquier otro conocimiento que tenemos), se procede a elucidar el contenido y la estructura de este conocimiento. En este sentido, entonces, la bioética se ve usualmente no como creación de conocimiento, sino como la elu- cidación del conocimiento que ya tenemos y la aplicación de lo que hemos aprendido de dicha elucidación a situaciones de las cuales no tenemos un conocimiento claro.

Este es un lugar muy usual para considerar la intersección de bioética y religión. No es este el caso en que cada una de las concepciones políticas principales abrazará las nociones de respeto a las personas, justicia y beneficencia: algunas formas de tiranía, como Platón enseñó y muchos dictadores lo han demostrado desde entonces, reducen el respeto a algo que sólo uno se merece, la justicia a la voluntad de uno y la beneficencia como la consideración del "bien" de uno. $Y$ todavía otra vez, el conocimiento que tuvimos a raíz de los procesos de Nuremberg no fue un conocimiento cuya verdad dependiese de que tuviéramos un poder superior, ni tampoco era un conocimiento que sólo dependiera de si uno fuera o no capaz de tener dicho conocimiento. El conocimiento ético que tuvimos era que aun si Hitler fue capaz de seguir y conquistar el mundo entero, las atrocidades nazis eran malas e incluso si los experimentos nunca hubieran salido a la luz, aún serían malos.

Las religiones del mundo están unidas en aceptar a la gente como digna de respeto, a la justicia como una obligación que se sigue de la voluntad de Dios y a la beneficencia como la respuesta correcta de la gratitud. Esta unidad en el mensaje por sí solo le da a la religión un 
carácter único, comparada, por ejemplo, a la político o a los negocios, y por un esfuerzo como el de la bioética que afronta el desafío de hablar sobre esos temas en un medio heterogéneo, la unidad de voz con la que la religión articula el valor de las personas y las razones por las que deben respetarse y la búsqueda de su bien como un asunto de interés para la bioética. Esto, por supuesto, no equivale a decir que la historia de la religión ha sido una historia uniforme en la que se ha mostrado respeto, justicia y beneficencia; es solamente decir que cuando se mira al cristianismo, al judaísmo, al islamismo, al hinduismo, al budismo o al confucianismo, se encuentran nociones plenamente articuladas de respeto, justicia y consideración del bien de las demás personas. Este es el origen y la raíz más profunda de dichas ideas. Para aquellos que se encuentran formando parte activa de una tradición religiosa, mantener la memoria y la comprensión de la forma en la que los conceptos fundamentales de la bioética brotan y están arraigados en la historia y la sustancia de la religión es una forma para que las ideas éticas se mantengan vivas y sean persuasivas. Abstraídas de sus raíces, pierden su carne. Cuando, por ejemplo, un cristiano narra la historia del Buen Samaritano y a partir de esto se desplaza hacia la idea de respeto a las personas, la justicia y la beneficencia, estas ideas tienen una significación que se enlaza con la comprensión cristiana de cómo son las cosas y cómo estas ideas éticas se entretejen con el hilo de las cosas.

Aún aquellas personas que no están dentro de una tradición religiosa, pero están comprometidas en la bioética, hacen bien en entender las formas en que las ideas centrales están arraigadas en las tradiciones de la fe y en las maneras en que las ideas se han experimentado como conocimiento. De esta forma, una persona puede profundizar en su comprensión del uso de estos conceptos cuando, al abstraerlos de su contenido religioso, se pregunta cómo los valores aparecen en el horizonte del asunto, cómo la justicia persuade, cómo el bien del otro se convierte en mi preocupación moral y por qué los fines que deseo no justifican interrumpir los fines que otra persona desea. Todas las personas que están sentadas en la mesa de discusión hablan desde una perspectiva aventajada. Para aquellos que no hablan desde una perspectiva religiosa, el hecho de comprender la sustancia de las nociones éticas al margen de los artículos de fe es una forma importante para que sus puntos de vista se vuelvan sólidos. Un jesuita y un ateo que hablan como tales pueden tener una conversación mucho más honesta e interesante sobre un tema que plantea un desafío ético que un jesuita y un ateo que pretenden hablar desde un punto de vista indeterminado. La religión puede formar parte de esta conversación sobre la ética al identificar los relatos religiosos que moldean muchos 
puntos de vista y al motivar a aquellos que parecen estar hablando "desde ningún lugar" a identificar sus propios relatos y a reivindicar la pertenencia y la validez de la fuente de sus convicciones.

\section{La bioética, la religión y la idea de los fines}

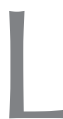

a bioética puede decir que debemos respetar a las personas, - pero sin la religión la pasa ma tratando de decir qué es una persona, tal como se ve en los debates sobre el aborto y la eutanasia.

En el concepto de beneficencia, la bioética puede proponer la noción de que debemos actuar en una forma en la que no se dañen a otros y que sea consistente con los intereses y las metas de lo que debería ser el humano. Esto no es sorprendente ni es malo. La religión, por otra parte, tiene como parte central de su naturaleza plantearse las preguntas de quiénes somos, cuáles son las metas propias del género humano, qué es lo que Dios pide de nosotros y nos da a nosotros, qué es lo que podemos esperar y cómo deberíamos vivir nuestras vidas. No puedo decir si una mujer debe practicarse un aborto o no sin antes entender más acerca de lo que es el sexo, cómo debemos usarlo, por qué tenemos hijos y si hay bienes en competencia para cuya consecución Dios requiere que abortemos a un bebé, entre otras cosas. La bioética puede decir que debemos respetar a las personas, pero la religión puede darle contenido a las ideas sobre lo que constituye a una persona y acerca de qué es lo que hace de una meta o de un fin algo moralmente bueno.

La religión nos narra una historia completa. Cuenta una historia sobre el lugar de dónde procedemos y hacia dónde vamos. Nos narra historias acerca de cómo el dinero debe valorarse y usarse y cómo deben tratarse a los cuerpos. Nos dice mucho acerca de la muerte, la fidelidad, de vivir con otras personas y porqué tenemos un sentido tan profundo del significado de las cosas. Ofrece una explicación para el todo, y esto, por sí mismo, puede ofrecer un contraste útil a la bioética, la cual tiene un campo de preocupaciones mucho más definido, pero que se dirige a preocupaciones que no pueden discutirse adecuadamente sin referirnos a una explicación del todo.

Comprender la ética de los fines significa comprender a las personas completas, puesto que aparte de la persona completa no se puede ofrecer una explicación adecuada de lo que constituye un bien para dicha persona. La bioética suele referirse a los derechos que están incrustados en la ley, consenso o precedente. Pero necesariamente, entre más amplio sea el consenso, los principios deben ser más generales. A la hora de aplicar los 
principios consensuados de respeto, justicia y beneficencia, descubrir medios de negociar los casos particulares puede sacar provecho de la familiaridad con la historia de cómo la religión negocia estos particulares en referencia a una fe, a una visión de mundo y a un sentido de quién es uno en relación con el universo tal como fue creado y en relación con los toros que están en una comunidad religiosa. Más aún, muchas tradiciones religiosas están profundamente comprometidas desde dentro de la fe para dar una buena respuesta a aquellos que están fuera de la fe, y frecuentemente las nociones religiosas como la hospitalidad y la apertura para recibir al forastero como si se estuviera recibiendo a Dios o a un ángel son nociones que ejemplifican el respeto, la justicia y la beneficencia. Esta práctica concreta con su larga historia es una fuente potencialmente rica de comprensión para los principios nucleares que se han diseminado en el pasado siglo de trabajo en la bioética.

Con frecuencia, dichas prácticas tienen un impacto tremendo que no abarca solamente a comunidades de fe específicas, sino, como ocurre en ciertos países donde la práctica religiosa es muy difundida, a través de una cultura entera. Esto tiene consecuencias importantes para la adaptación de principios más generales en bioética, como en el caso del CIOMS a la cultura particular en la cual se lleva a cabo la práctica o la investigación mé- dicas. La autonomía, por ejemplo, es una noción que tiene una larga historia tanto en la filosofía como en la religión y la prioridad de la legislación propia puede variar de una tradición a otra. No hay un punto de vista de ninguna parte $y$ la bioética se adapta siempre a un contexto y una cultura particular. Así como el desarrollo de la bioética en los Estados Unidos, por ejemplo, ha sido moldeado por un énfasis contextual en la filosofía de la democracia liberal y el individualismo, un país configurado por la presencia del cristianismo, el judaísmo, el islamismo, etcétera, adaptará necesariamente los principios de forma distinta.

Una manera muy útil de pensar acerca de la bioética es desde un lugar donde la gente con voces diferentes y diferentes compromisos viene junta con un proyecto común que requiere esto: el proyecto de sanar, por ejemplo, o el de cuidar a los moribundos cuando ya no somos capaces de sanarlos. Al concebir la bioética de esta manera, no se convierte en un precipitado de los muchos puntos de vista particulares en un juego de proposiciones que, o bien tienen demasiada particularidad, al grado en que se convierten en la voz de un solo grupo en vez de un lenguaje de negociación, o se vuelve algo tan general que, mientras casi todo mundo concuerda con los preceptos, estos no sirven para enfrentar ninguno de los desafíos éticos actuales. 
La mayoría de comunidades religiosas, al tener un conjunto de creencias propias, se considera a sí misma como comunidad viva que crece al comprometerse con desafíos nuevos e imprevistos. Lo precedente proviene de, las historias están referidas a, las oraciones se ofrecen por la sabiduría - pero no se asume que cualquier escritura tiene respuestas explícitas a preguntas como si las células madre totipotent desarrolladas a partir de la manipulación genética de células madre diferenciadas pueden usarse para intervenir en lesiones de la médula espinal o en el mal de Parkinson. Esta práctica de una comunidad comprometida con dichos temas para encontrar "cómo respondemos a esta pregunta" es una práctica que es lo suficientemente ubicua al punto que aquellas personas interesadas en el campo de la bioética la ignoran a su propia cuenta y riesgo si quieren que sus esfuerzos sean relevantes como opciones reales de seres humanos comprometidos. Cualquiera que haya dado una clase de bioética sabe esto: los estudiantes constante, predecible y correctamente extraen sus propios compromisos morales cuando están comprometidos con un tema y la conversación es mucho más rica que cuando el vocabulario del compromiso se limita al lenguaje del informe Belmot, por muy útil que haya sido este documento. Una vez que este tipo de compromiso se ve como positivo en el campo de la bioética, súbitamente hay una con- versación de muchos miles de años de la cual puede partir la bioética.

El valor va por otra vía. El gran beneficio que se deriva de la madurez del campo de la bioética es que no hay una sola tradición a la que le pertenezca. Sí, hay una bioética cristiana, una bioética judía, una bioética musulmana y una bioética marcadamente atea tal como la de Pete Singer, pero el campo en sí mismo se vuelve la oportunidad para que todos se sienten a la mesa y, de hecho, va más allá, diciendo que esas decisiones deben tomarse - puesto que no tomar una decisión es ya hacer una decisión. Es mejor tener muchas voces involucradas que tan sólo unas pocas.

Los cristianos y aquellas otras personas adscritas a otras tradiciones de fe han lidiado con las cuestiones morales suscitadas por el cuidado mérito durante siglos antes de que la idea de la "ética médica" se convirtiera en un campo reconocido. La gente "religiosa" y, más específicamente, la Iglesia han tratado de responder a las preguntas morales de la medicina en una forma que explique quién es Dios con relación a los seres humanos. Por ejemplo, en la perspectiva histórica del catolicismo, la ética médica utiliza las herramientas intelectuales de la teología moral fundamental y las aplica a situaciones clínicas. Los componentes de la ley moral para los cristianos son el derecho natural, la ética filosófica, la revelación divina y las enseñanzas de la Iglesia. Pero a lo largo de la historia, mu- 
chos grupos religiosos sumamente diferentes han intentado formular las virtudes centrales del cuidado médico de muchas maneras. Pese a que estas formulaciones no son en modo alguno idénticas, suele haber áreas importantes de consenso, especialmente en las ideas fundamentales que subyacen a las respuestas específicas a los temas desafiantes éticamente hablando.

La Iglesia Católica Romana y las denominaciones protestantes tienen puntos de vista bien desarrollados sobre un espectro de temas sobre ética médica. Sumado a ello, hay vastas enseñanzas religiosas no cristianas sobre ética médica. Las éticas médicas judía e islámica, por ejemplo, articulan los deberes y responsabilidades de los médicos judíos e islámicos y en el Este asiático y la India, las tradiciones de la ética médica están entrelazadas con el taoísmo, el confucianismo, el sintoísmo y el hinduismo.

Es útil enfocarse en un ejemplo concreto, de los muchos que pueden elaborarse a partir de varias tradiciones. Los cristianos están Ilamados a usar la vida de Jesús como modelo para su perspectiva de todas las áreas de la vida, incluyendo el cuidado del cuerpo físico. Cuando Jesús envió a los setenta en el evangelio de Lucas, para proclamar la buena nueva del reino de Dios, él les dijo: "Cuando entren a una ciudad y su pueblo les dé la bienvenida, coman lo que la gente les ponga adelante; cuiden a los enfermos que haya en ella y díganles: 'El Reino de
Dios está cerca'" (Lucas 10: 8-9). Cuando Jesús estaba predicando ante una gran multitud en Marcos, capítulo 8, dijo: "Siento lástima por la muchedumbre, porque han estado conmigo durante tres días y no tienen nada que comer". Tomó entonces siete porciones de pan y unos cuantos pescados y los bendijo, lo que le permitió que alimentaran a cuatro mil personas. En esencia, no era suficiente para Jesús el limitarse a predicarle a esta gente, sino también satisfacer sus necesidades físicas. Jesús nunca se dirigió a alguien que estuviera hambriento o enfermo para decirle: "Dios te ama" o "el Reino de Dios está cerca" para después irse. Jesús sanó a los enfermos que conoció y alimentó a los hambrientos, mientras que proclamaba que el Reino de Dios estaba cerca. Esta valoración de la gente con que nos encontramos es una motivación profunda y fundamental para el compromiso cristiano con los asuntos éticos y es poderosa, tanto como contexto para la discusión así como un incentivo para la acción concreta.

Las cosas no son simples, sin embargo. La Iglesia es una institución y ha estado sujeta a lo largo de la historia a la corrupción. Sus dirigentes han sido acusados de usar la autoridad divina para alcanzar beneficios políticos o personales. Las diferentes tradiciones han interpretado las mismas escrituras de formas muy distintas, lo cual provoca desunión acerca de temas como la ética médica. ¿Es posible 
seguir juntos como Iglesia y tener un impacto en las discusiones sobre ética médica?

Cualquiera que sea la respuesta a esta pregunta, hay una pregunta más acerca de cómo las tradiciones religiosas concretas se comprometen activamente con la bioética secular y hay precedentes para que los pensadores se muevan del contexto de las tradiciones religiosas hacia un campo más neutral, en el que un abanico más amplio de influencias pueden tomar parte para resolver problemas sumamente arduos.

Un importante ejemplo es el de Daniel Callahan, quien puso su experiencia personal como una forma de ilustrar la secularización de la bioética. Cuando Callahan exploró por primera vez la bioética a mediados de los años 60, las únicas fuentes disponibles eran la teología y la tradición de la medicina que había estado fuertemente influida por la religión. La expresión pública de la Iglesia Católica Romana sobre temas de procreación y de población en los 70, resultó problemática para Callahan. Más en concreto, el giro conservador del catolicismo después del Vaticano II influyó para que Callahan volviera su atención al ámbito secular para buscar fuentes que le permitieran enfrentar con la ética biomédica, especialmente en el aborto, en los temas reproductivos y en el control de la natalidad. Se convenció de que no podía trabajar de forma efectiva dentro de la Iglesia, así que estableció su grupo de reflexión laico sobre la bioética, el Centro Hastings.

Sin embargo, las tradiciones de fe tienen mucho que ofrecer en el campo de la bioética. Quizá una de las influencias morales más significativas del cristianismo está relacionada con su énfasis en el amor para el prójimo y en la compasión para los enfermos. Las instituciones religiosas han establecido muchos hospitales para los enfermos y los desahuciados y la enseñanza cristiana pone especial énfasis en que los médicos deben cultivar la compasión y la caridad. Un tratado de principios del siglo XII exhorta a los doctores a no "sanar por amor a la ganancia, ni tratar con mayor consideración a los ricos que a los pobres, o a los nobles que a los plebeyos". Esta es una poderosa influencia moral y la perspectiva de la "iglesia pública" puede ofrecer algunos indicios sobre una forma en que la gente de una perspectiva religiosa puede juntarse y unificarse para trabajar hacia el bien común respetando las diversas tradiciones de fe.

Una respuesta efectiva para el desafío de las fuerzas de la secularización y el pluralismo es el concepto teológico de la iglesia pública. La iglesia pública está "en el mundo pero no es del mundo". La iglesia pública es la iglesia tal como se entiende comúnmente, pero tiene una consciencia especial de su misión pública: el bien común. Esta iglesia no sólo está preocupara por sí misma, sino también por las necesida- 
des de la sociedad pluralista. Algo de este pluralismo se encuentra dentro de esta iglesia, que trabaja cooperativamente con otros agentes y otras fuerzas por el bien. Estas personas se encuentran asociadas con la lucha de Dios en contra del dolor, la pérdida y la muerte. Esta consciencia se expresa mediante la estructura organizacional de la iglesia. Gandhi sugirió algunos de los significados de la iglesia pública en su conocida afirmación "Quien separa la religión de la política no entiende ni a la religión ni a la política". La iglesia pública es tanto particular (cristiana) como universal. No sólo se dedica a reclutar nuevos miembros, sino a llamar a la congregación pública a que satisfaga las necesidades del extranjero y del vecino. La teología de la iglesia pública es una estrategia para subrayar la dimensión normativa de la Iglesia. Mucha de la dimensión normativa es una consciencia teológica que debe expresarse por medio de las estructuras organizacionales, desde arriba hacia abajo, de la iglesia pública. La dimensión normativa de la Iglesia y la religión no sólo es privada y personal, sino también pública y social.

El libro de Stanley Hauerwas, Suffering Presence, ofrece pistas sobre la discusión acerca del "don de la medicina" en relación con el propósito y la presencia de Dios. "Más aún, yo creo que las preguntas suscitadas por la atención médica son precisamente aquellas que necesitan más recursos teológicos".
El que la medicina y religión estén interrelacionadas es algo que no puede soslayarse. La pregunta es de qué manera, exactamente, hacemos esto. La medicina proporciona un poderoso recordatorio a los cristianos de que nuestra "naturaleza" como seres corpóreos está asediada por la enfermedad y destinada a la muerte. Aunque la medicina también nos recuerda que esta es nuestra "naturaleza" (como cristianos, pero más específicamente como la "iglesia") ser una comunidad que rechaza dejar que el sufrimiento nos aliene a unos de otros. Reclamar el significado moral del sufrimiento no significa que estemos comprometidos a negar la intervención de la medicina para aliviar el sufrimiento. Lo que ello exige es que aprendamos a entender de otra manera qué es lo que estamos haciendo cuando intervenimos médicamente para quitar el sufrimiento.

Puesto que la meta de cualquier discusión útil sobre bioética es, finalmente, enfrentar la cuestión de cuántas voces pueden escucharse en la discusión sobre temas éticos complejos sin silenciar a una, o ignorar a otra, o sin perder el valor profundo que tienen las largas historias que están detrás de las ideas religiosas relacionadas con la ética, quizás es adecuado terminar con una voz que causará sorpresas y que no es muy citada en los textos sobre bioética, la de Bono, del grupo US: "Pero la única cosa en que podemos estar de acuerdo todos, todas las creencias, todas las 
ideologías, es que Dios está con los vulnerables y los pobres. Dios está en las chabolas, en las cajas de cartón donde los pobres tienen su casa... Dios es el silencio de una madre que ha infectado a su hijo con un virus que terminará con las vidas de ambos... Dios está en los gritos que se escuchan debajo del estruendo de la guerra... Dios está en los desechos de las oportunidades y las vidas desperdiciadas, y Dios está con nosotros, si nosotros estamos con ellos".

La religión puede ayudarnos a entender cómo estamos relacionados unos con otros y nos cuidamos mutuamente $y$, al final, hacer esto bien es el corazón y el alma de la buena bioética. Lo que nuestra religión nos dice sobre las relaciones humanas puede moldear profundamente la forma en que pensamos sobre la ética en la medicina. Puesto que las diferentes culturas y religiones entienden las relaciones humanas de manera diferente, todos debemos acudir a la mesa para encontrar nuestras creencias fundamentales en común sobre la naturaleza de la humanidad y las relaciones, mientras nos encontramos abiertos y respetuosos hacia otras culturas y puntos de vista que desafíen nuestras creencias, incluyendo aquellas "creencias" que subyacen a la bioética secular. 